\title{
Supplementary feeding with either ready-to-use fortified spread or corn-soy blend in wasted adults starting antiretroviral therapy in Malawi: randomised, investigator blinded, controlled trial
}

\author{
MacDonald J Ndekha, nutritionist, ${ }^{1}$ Joep J G van Oosterhout, associate professor, ${ }^{2}$ Eduard E Zijlstra, professor, ${ }^{2}$ \\ Micah Manary, student, ${ }^{4}$ Haroon Saloojee, research physician, ${ }^{3}$ Mark J Manary, professor and senior \\ scientist ${ }^{1,4,5}$
}

\begin{abstract}
${ }^{1}$ Department of Community Health, College of Medicine, University of Malawi, Blantyre, Malawi

${ }^{2}$ Department of Medicine, College of Medicine, University of Malawi, Blantyre, Malawi

${ }^{3}$ Department of Paediatrics, University of the Witwatersrand, Johannesburg, South Africa

${ }^{4}$ Department of Pediatrics, Washington University School of Medicine, St Louis, USA

${ }^{5}$ Children's Nutrition Research Center, Baylor College of Medicine, Houston, Texas, USA

Correspondence to: M Manary, Department of Pediatrics, St Louis Children's Hospital, One Children's Place, St Louis, MO 63110 USA

manary@kids.wustl.edu
\end{abstract}

Cite this as: BMJ 2009;338:b1867 doi:10.1136/bmj.b1867

\section{ABSTRACT}

Objective To investigate the effect of two different food supplements on body mass index (BMI) in wasted Malawian adults with HIV who were starting antiretroviral therapy.

Design Randomised, investigator blinded, controlled trial.

Setting Large, public clinic associated with a referral hospital in Blantyre, Malawi.

Participants 491 adults with BMI $<18.5$.

Interventions Ready-to-use fortified spread $(n=245)$ or corn-soy blend ( $n=246)$.

Main outcome measures Primary outcomes: changes in $\mathrm{BMI}$ and fat-free body mass after 3.5 months. Secondary outcomes: survival, CD4 count, HIV viral load, quality of life, and adherence to antiretroviral therapy.

Results The mean BMI at enrolment was 16.5. After 14 weeks, patients receiving fortified spread had a greater increase in BMI and fat-free body mass than those receiving corn-soy blend: 2.2 (SD 1.9) v 1.7 (SD 1.6) (difference $0.5,95 \%$ confidence interval 0.2 to 0.8 ), and 2.9 (SD 3.2) v 2.2 (SD 3.0) kg (difference $0.7 \mathrm{~kg}, 0.2$ to $1.2 \mathrm{~kg}$ ), respectively. The mortality rate was $27 \%$ for those receiving fortified spread and $26 \%$ for those receiving corn-soy blend. No significant differences in the CD4 count, HIV viral load, assessment of quality of life, or adherence to antiretroviral therapy were noted between the two groups.

Conclusion Supplementary feeding with fortified spread resulted in a greater increase in BMI and lean body mass than feeding with corn-soy blend.

Trial registration Current Controlled Trials ISRCTN67515515.

\section{INTRODUCTION}

The prevalence of wasting, defined as a body mass index $(\mathrm{BMI})<18.5$, in adults with advanced HIV infection in sub-Saharan Africa is 20-40\%. ${ }^{12}$ Wasting can be the result of inadequate nutrient intake, either from anorexia or food insecurity associated with poverty, a catabolic state induced by opportunistic infection or malignancy, or poor absorption of nutrients secondary to diarrhoea and malabsorption. Because food insecurity is common in sub-Saharan Africa ${ }^{3-5}$ and an adequate diet is believed to be important for adherence to antiretroviral therapy ${ }^{67}$ supplementary feeding in conjunction with treatment is advocated as standard in the care of wasted adults with HIV in Malawi. In sub-Saharan Africa mortality during the first months of antiretroviral therapy settings is high, and a low $\mathrm{BMI}$ is an independent risk factor for this early mortality. ${ }^{8}$ Supplementary feeding might therefore improve outcomes in patients receiving antiretroviral therapy because it ameliorates food insecurity. Evidence to support the effectiveness of this practice, however, is limited, and there have been no published controlled trials showing the benefit of such food supplementation in settings with limited resources, whether people are receiving antiretroviral therapy or not. $^{9}$

The most commonly available supplementary food in food aid programmes is corn-soy blended flour, an inexpensive fortified cereal-legume combination that requires cooking and has been widely used in Africa for decades. Corn-soy blend, however, has been associated with disappointing results in supplementary feeding programmes among children, pregnant women, and adults with HIV in sub-Saharan Africa. ${ }^{1011}$ In a recent study in urban Malawi among adults with late stage HIV infection who were not receiving antiretroviral therapy, corn-soy blend had no effect on mortality or clinical complications. ${ }^{12}$ Specialised, energy dense ready-to-use fortified spreads have also been recommended for feeding wasted adults with HIV. This spread is a pre-cooked, energy dense, lipid paste made from peanuts that resists bacterial contamination. ${ }^{13} \mathrm{~A}$ fortified spread has been formulated to deliver the same nutrients as the milk based therapeutic food F-100 for severely malnourished children, and its use has been associated with better 


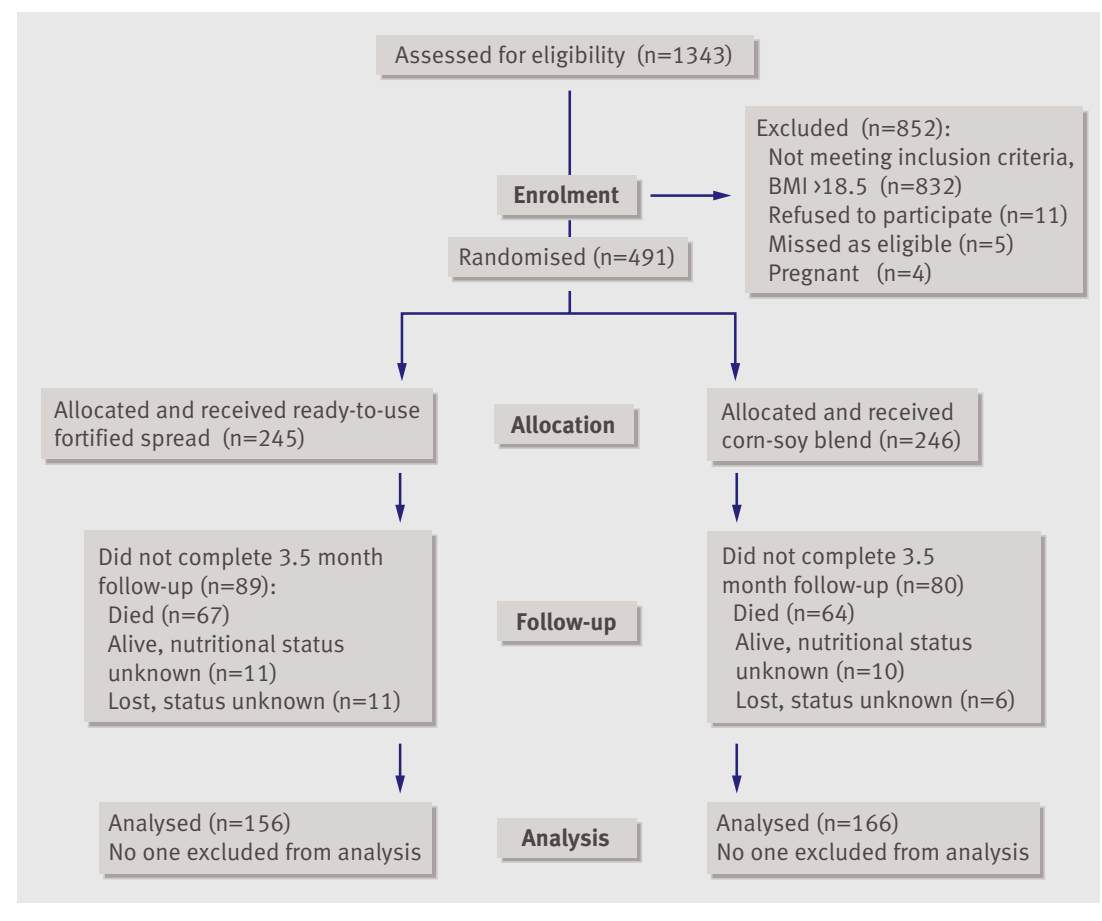

Fig 1 | Study flow diagram logistics to implement this policy were not in place until 2007.

\section{Study design}

This was a randomised, investigator blinded, controlled effectiveness trial of supplementary feeding with either corn-soy blend or fortified spread. Randomisation took place with sealed, unmarked opaque envelopes that were allocated to participants in an area separate from the research and treatment room by using block randomisation of 50 numbers. The envelopes contained a card with a unique number from 1 to 500. A designated staff member matched the number with the food assignment and dispensed the appropriate food during the intervention period. Participants were not blinded to the food assignment because the blended flour was distinct in appearance compared with the peanut paste. All the other staff members, including the clinicians managing the antiretroviral therapy programme and the nutritionist, were blinded to the dietary assignment. The food supplements were distributed monthly in conjunction with clinic follow-up visits, and each of the study participants remained within the group to which they were assigned for the duration of the study. Food supplements were started at the same time as antiretroviral therapy and given for a period of 14 weeks. Participants returned for follow-up two weeks after the start of the study and monthly thereafter.

Our primary outcomes were changes in the BMI and the fat-free body mass after 14 weeks. Secondary outcomes were nutritional status, defined as well nourished (BMI $\geq 18.5$ ), moderately wasted (BMI 16$<18.5)$, severely wasted $(\mathrm{BMI}<16)$, death, alive/nutritional status unknown, and lost to follow-up. Additional secondary outcomes were quality of life, serum albumin concentration, haemoglobin concentration, CD4 count, HIV viral load, and adherence to antiretroviral therapy.

The sample size of 450 enabled detection of a difference in BMI and fat-free body mass of $0.5 \mathrm{~kg}$ between the two groups with $95 \%$ specificity and $80 \%$ power. We allowed for 15\% attrition because of pregnancy, losses to follow-up, and death.

\section{Study procedures}

On enrolment, we obtained informed consent and demographic, clinical status, quality of life, and anthropometric measurements; measurements included weight, height, mid-upper arm circumference, waist circumference, and bioelectrical impedance. Participants had their bioelectrical impedance measured when they presented to the clinic for care, without regard to ambient conditions or the time of day. Those who seemed clinically ill were assumed to be at risk for dehydration, and a bioelectrical impedance measurement was not recorded.

Clinical officers supervised provision of antiretroviral therapy. Participants were subsequently seen at the clinic on four occasions during the study: after two, six, 10, and 14 weeks. During each visit nevirapine, stavudine, and lamivudine. Routine prophylaxis with co-trimoxazole before and during antiretroviral therapy had not been fully implemented at the time of the study. It was approved as a standard treatment by the Ministry of Health in 2006, but the 
trained study staff assessed clinical status, administered questionnaires on quality of life and adherence to antiretroviral therapy, and measured body weight, bioelectrical impedance, and waist and mid-upper arm circumferences. They collected information on quality of life with a locally adapted version of the 14 item CDC health related quality of life assessment. ${ }^{17}$ Adherence to treatment was measured with a local, previously validated questionnaire that consisted of four questions: did you miss a tablet the day, week, month, or ever before. ${ }^{18}$ Bioelectrical impedance measurements were done with the Quaatum 2000 device (RJL Systems, Clinton Township, Michigan). All measurements were carried out with standardised procedures.

Researchers took blood samples at enrolment and at 14 weeks to measure serum albumin concentration, haemoglobin concentration, CD4 count (FacsCount, Becton-Dickinson, Franklin Lakes, NJ, USA), and HIV viral load (Roche Amplicor; Roche, Basel. Switzerland; detection level 48 copies/ml).

Participants' diets on enrolment were assessed with a 24 hour dietary recall the day before enrolment. In addition, for each of the foods that the participants consumed the day before enrolment they were asked whether the foods were consumed daily, weekly, or monthly. Dietary intakes were assessed with three different methods: the total number of different foods consumed, whether animal products were consumed or not, and a 12 point dietary diversity score that has previously been validated and correlated with household food security. ${ }^{19}$

Table 1 | Nutrients provided by two food supplements, expressed as amount per day and compared with estimated average requirement (EAR) for adults

\begin{tabular}{|c|c|c|c|c|}
\hline & \multirow{2}{*}{$\begin{array}{l}\text { Fortified spread } \\
(245 \mathrm{~g} / \text { day })\end{array}$} & \multirow{2}{*}{$\begin{array}{l}\text { Corn-soy blended flour } \\
\text { (374 g/day) }\end{array}$} & \multicolumn{2}{|c|}{ EAR } \\
\hline & & & Women & Men \\
\hline Energy (kJ) & 5694 & 5694 & 13252 & 13252 \\
\hline Protein (g) & 35.5 & 50 & 46 & 56 \\
\hline Fat (g) & 91 & 26.2 & - & - \\
\hline Calcium (mg) & 830 & 258 & 1000 & 1000 \\
\hline Phosphorus (mg) & 700 & 1050 & 580 & 580 \\
\hline Magnesium (mg) & 240 & 500 & 255 & 330 \\
\hline Potassium (mg) & 2880 & 1700 & 4700 & 4700 \\
\hline Selenium $(\mu \mathrm{g})$ & 78 & 22 & 45 & 45 \\
\hline Zinc (mg) & 8 & 8 & 8 & 11 \\
\hline Copper (mg) & 0.9 & 2.9 & 0.9 & 0.9 \\
\hline Iron (mg) & 8 & 16 & 18 & 8 \\
\hline Vitamin A $(\mu \mathrm{g})$ & 710 & 1040 & 700 & 700 \\
\hline Vitamin C (mg) & 90 & 26 & 60 & 75 \\
\hline Vitamin D ( $\mu \mathrm{g})$ & 5 & 6 & 5 & 5 \\
\hline Vitamin E (mg) & 52 & 32.5 & 12 & 12 \\
\hline Niacin (mg) & 14 & 13 & 11 & 12 \\
\hline Folic acid $(\mu \mathrm{g})$ & 400 & 153 & 320 & 320 \\
\hline Thiamine (mg) & 1.1 & 1.3 & 0.9 & 1.0 \\
\hline Riboflavin (mg) & 1.3 & 0.8 & 0.9 & 1.1 \\
\hline Vitamin B-6 (mg) & 1.3 & 1 & 1.1 & 1.1 \\
\hline Vitamin B-12 $(\mu \mathrm{g})$ & 1.4 & 0.5 & 2.0 & 2.0 \\
\hline
\end{tabular}

Participants who failed to return for a scheduled clinic visit for antiretroviral therapy were visited at home within two months, and information regarding clinical status, compliance with treatment, and body weight and composition was collected. If the participant had died, the date and circumstances of death were ascertained by interviews with the closest relatives. Participants who could not be located were considered lost to follow-up.

After the supplementary feeding period ended social scientists from the University of Malawi, who were not involved in any other aspect of the study, led open ended focus group discussions to explore the use, acceptability, and sharing of the food supplements and to assess dietary compliance; groups averaged eight randomly selected study participants from both supplementary feeding groups.

\section{Study foods}

Table 1 shows the nutritional compositions of the two supplementary foods. Both supplementary foods provided the same level of energy because different amounts were used; the energy per unit higher in the fortified spread; neither provided amounts of micronutrients that significantly exceeded the estimated average requirement. The supplements were produced locally in accordance with international food safety specifications. The ready-to-use fortified spread was supplied in $245 \mathrm{~g}$ plastic bottles, and participants received one bottle a day. The amounts of each supplement given provided about $50 \%$ of the daily estimated average energy requirement, based on WHO nutritional guidelines that take into account that symptomatic adults with HIV/AIDS need 30\% more energy than healthy individuals. ${ }^{20}$ Both groups of participants were advised to consider the food supplements as part of their medical treatment and told that the food should not be shared with others.

\section{Statistical analysis}

The data were doubly entered on an Excel database. We calculated fat-free body mass using the equations developed by Kotler et al for wasted adults with HIV. ${ }^{21}$ These equations were used in our setting without validation. We calculated means and standard deviations for continuous parameters and used Fisher's exact test (two outcomes) or $\chi^{2}$ test (three or more outcomes) to compare dichotomous variables between participants in each supplement group. We used Student's $t$ test to compare continuous variables. $\mathrm{P}<0.05$ was considered significant for all comparisons.

BMI was measured at four subsequent points after enrolment (after two, six, 10, and 14 weeks), so the participant's recovery was assessed during each of these four distinct time intervals. We calculated the rate of change in BMI during each of these intervals for each participant. To determine whether the rates of change in BMI during the 14 week feeding period differed between the two food groups, we compared the mean change in BMI during each interval for each food group using Student's $t$ test. Weight gain 
Table 2 Initial status of wasted adults with HIV starting antiretroviral therapy. Figures are means (SD) unless stated otherwise

Fortified spread $(n=245) \quad$ Corn-soy blend $(n=246)$

Demographics:

\begin{tabular}{|c|c|c|}
\hline Age (years) & $36.0(11.0)$ & $36.0(12.0)$ \\
\hline No (\%) of women & $152(62)$ & $142(58)$ \\
\hline \multicolumn{3}{|l|}{ Anthropometric: } \\
\hline BMI & $16.5(1.5)$ & $16.5(1.5)$ \\
\hline Fat-free mass ( $\%$ of body composition) & $96.0(10.0)$ & $95.0(12.0)$ \\
\hline Fat-free body mass (kg) & $40.5(5.8)$ & $41.0(7.2)$ \\
\hline Mid-upper arm circumference (cm) & $20.4(2.2)$ & $20.8(4.1)$ \\
\hline Waist circumference $(\mathrm{cm})$ & $65.8(5.2)$ & $65.8(3.2)$ \\
\hline \multicolumn{3}{|l|}{ No (\%) by nutritional status: } \\
\hline Severely malnourished (BMI «16.0) & $81(33)$ & $81(33)$ \\
\hline Moderately malnourished (BMI 16.0-18.5) & $164(67)$ & $165(67)$ \\
\hline \multicolumn{3}{|l|}{ Laboratory results: } \\
\hline CD4 count (cells $\left.\times 10^{6} / \mathrm{l}\right)$ & $131.0(140.0)$ & $142.0(319.0)$ \\
\hline Albumin $(\mathrm{g} / \mathrm{l})$ & $24.0(8.0)$ & $24.0(4.0)$ \\
\hline Haemoglobin $(\mathrm{g} / \mathrm{l})$ & $96(20)$ & $98(57)$ \\
\hline No (\%) who received co-trimoxazole prophylaxis & $151(62)$ & $137(56)$ \\
\hline \multicolumn{3}{|l|}{ Quality of life: } \\
\hline General health (1=excellent, $5=$ =poor) & $4.5(0.7)$ & $4.5(0.8)$ \\
\hline Physically unhealthy days/month & $17.6(11.8)$ & $16.2(11.3)$ \\
\hline Mentally unhealthy days/month & $6.1(9.4)$ & $6.4(10.0)$ \\
\hline Mental/physical limitation days/month & $12.7(12.9)$ & $13.2(13.1)$ \\
\hline \multicolumn{3}{|l|}{ Diet: } \\
\hline Dietary diversity score (range $0-12$ ) & $2.9(1.4)$ & $2.8(1.4)$ \\
\hline No (\%) who consumed animal products within $24 \mathrm{hrs}$ & $66(26)$ & $62(25)$ \\
\hline No of different foods consumed within 24 hrs & $8.6(4.0)$ & $7.8(3.7)$ \\
\hline
\end{tabular}

during recovery from wasting follows an exponential decay pattern ${ }^{22}$; when individuals are more wasted they regain weight faster, and as they approach a normal BMI, the rate of weight gain decreases. Given this, we used the mean values for change in BMI for each food group from this study to determine the shape of the BMI recovery curve, using an exponential modeling program (GraphPad Prism 3.03).

We assessed the association between death and demographic, anthropometric, and immunological characteristics by Cox regression modeling. The covariates considered were sex, age, type of supplementary food, receipt of co-trimoxazole, BMI, fat-free body mass, $\mathrm{CD} 4$ count, haemoglobin concentration, and albumin concentration at enrolment. Participants who were given co-trimoxazole as prophylaxis at any time during the study period were considered as having received it in the regression analysis. SPSS version 13.0 (Chicago, IL) statistical software was used.

Participants were stratified into thirds for the three different measures of dietary intake, and we compared the change in BMI for those receiving fortified spread and corn-soy blend between each third to determine whether supplementary feeding was more beneficial among participants with more food insecurity.

\section{RESULTS}

We enrolled 491 participants (97\%) of all eligible individuals during the study period) (fig 1 ). There were no significant differences in the demographic, anthropometric, or clinical characteristics between the two study groups at baseline (table 2). Seventeen (3.4\%) participants were lost to follow-up, and $21(4.3 \%)$ were known to be alive but missed their 3.5 month clinic visit and no anthropometric measurements were made. No adverse reactions to either food were reported.

After 14 weeks of nutritional intervention and antiretroviral therapy participants who received fortified spread had a greater increase in BMI, fat-free body mass, and mid-upper arm circumference than those who received corn-soy blend (table 3). Fat-free mass contributed to $2.9 \mathrm{~kg}(51.8 \%)$ of the $5.6 \mathrm{~kg}$ weight gain in the fortified spread group and $2.2 \mathrm{~kg}(51.2 \%)$ of the $4.3 \mathrm{~kg}$ weight gain in the corn-soy blend group. There were no significant differences in survival, HIV viral load strata, $\mathrm{CD} 4$ count, or quality of life between the groups.

Mortality was high in both groups: 131 (27\%) participants died within the first 14 weeks. Male sex, not receiving co-trimoxazole prophylaxis, and a lower BMI, haemoglobin, or albumin on enrolment were independent risk factors of death at 14 weeks (table 4).

Self reported adherence to antiretroviral therapy was similar in both groups at each follow-up visit. Few participants reported missing a dose on the previous day $(3 / 167(1.8 \%) v 2 / 176(1.2 \%), \mathrm{P}=0.5)$ or at least one dose in the previous week (8/167 (4.8\%) v 8/ $176(4.5 \%), \mathrm{P}=0.5)$ in the fortified spread and corn-soy blend groups, respectively.

Mathematical modelling of change in BMI between each measurement interval in each group showed that the coefficient in the exponential term in the two models was similar (fig 2). Thus the rate of change in BMI decreased during the supplementation period (fig 2), but the change in BMI was greater by a constant amount in the fortified spread group (0.045) compared with the corn-soy blend group throughout the entire supplementation period. Exponential decay models fit both datasets well $\left(\mathrm{r}^{2}=0.98\right)$, although these datasets consist of only four points.

We examined outcomes in subgroups of participants stratified by the quality of their diet on enrolment and the type of supplementary feeding (table 5). Neither corn-soy blend nor fortified spread affected any dietary subgroup differently; diet on enrolment had no effect on outcome or on the benefit of either supplement.

Ninety five participants attended 12 focus group discussion sessions; 42 of whom received fortified spread and 53 corn-soy blend. Both study food supplements were universally highly appreciated. Nearly all participants said that sharing of both food supplements by dependents and family members was common, although corn-soy blend was more likely to be shared because it needed preparation by caregivers before consumption.

\section{DISCUSSION}

In wasted patients starting antiretroviral therapy, food supplementation with ready-to-use fortified spread resulted in a greater increase in BMI, fat-free body 
mass, and mid-upper arm circumference than corn-soy blend after 14 weeks. There were, however, no differences observed in mortality, CD4 count, HIV suppression, adherence to antiretroviral therapy, or quality of life between the groups. Weight gain with supplementary feeding was considerable, resulting in gains of $10 \%$ and $13 \%$ of initial body mass for corn-soy blend and fortified spread, respectively.

\section{Limitations and major findings}

Our study was limited in that food consumption was not observed in either of the groups, therefore we do not know the degree of adherence with the dietary recommendations. However, this was an effectiveness study, as opposed to an efficacy study, to determine which of the two supplementary foods leads to better outcomes when provided to patients in an operational setting with limited resources. As we did not have a control group of participants receiving no supplementary food, we do not know what the nutritional status would have been without supplementary feeding. Although we included a control group in the original proposal, this was deemed unethical by the review

\begin{tabular}{|c|c|c|c|}
\hline & $\begin{array}{l}\text { Fortified spread } \\
\qquad(n=245)\end{array}$ & $\begin{array}{l}\text { Corn-soy blend } \\
\quad(n=246)\end{array}$ & $\begin{array}{l}\text { Difference } \\
(95 \% \mathrm{Cl})\end{array}$ \\
\hline \multicolumn{4}{|l|}{ Anthropometric: } \\
\hline Gain in BMI & $2.2(1.9)$ & $1.7(1.7)$ & $0.5(0.2$ to 0.8$)$ \\
\hline Gain in fat-free body mass (kg) & $2.9(3.2)$ & $2.2(3.0)$ & $0.7(0.2$ to 1.2$)$ \\
\hline Gain in mid-upper arm circumference (cm) & $2.2(2.0)$ & $1.6(1.7)$ & $0.6(0.3$ to 0.9$)$ \\
\hline Weight gain (kg) & $5.6(4.8)$ & $4.3(4.0)$ & $1.3(0.5$ to 2.1$)$ \\
\hline BMI $\left(\mathrm{kg} / \mathrm{m}^{2}\right)$ & $19.0(2.1)$ & $18.4(1.1)$ & $0.6(0.3$ to 0.9$)$ \\
\hline Fat-free body mass (\% of body composition) & $89.0(8.0)$ & $91.0(8.0)$ & $2.0(0.6$ to 3.4$)$ \\
\hline \multicolumn{4}{|l|}{ No (\%) by clinical/nutritional status: } \\
\hline Severely malnourished & $10(4)$ & $12(5)$ & $-1(-5$ to 2$)$ \\
\hline Moderately malnourished & $53(22)$ & $69(28)$ & $-6(-14$ to 1$)$ \\
\hline Well nourished & $93(38)$ & $85(35)$ & $3(-5$ to 12$)$ \\
\hline Died & $67(27)$ & $64(26)$ & $1(-6$ to 9$)$ \\
\hline Alive nutritional status unknown & $11(4)$ & $10(4)$ & \\
\hline Lost to follow-up & $11(4)$ & $6(2)$ & \\
\hline Admitted to hospital in first 12 weeks & $30(12)$ & $31(13)$ & $-1(-6$ to 5$)$ \\
\hline \multicolumn{4}{|l|}{ Laboratory results: } \\
\hline CD4 count (cells $\left.\times 10^{6} / \mathrm{l}\right)$ & $289(185)$ & $297(447)$ & $-8(-69$ to 53$)$ \\
\hline Increase in CD4 count (cells $\times 10^{6} /$ l) & $168(145)$ & $150(139)$ & $18(-7$ to 43$)$ \\
\hline \multicolumn{4}{|l|}{ No (\%) by HIV viral load: } \\
\hline$\langle 50$ copies/ml & $96(39)$ & 97 (39) & \multirow{3}{*}{$\begin{array}{c}\mathrm{P}=0.98 \text { for } \\
\text { trend }\end{array}$} \\
\hline $50-1000$ copies/ml & $59(24)$ & $62(25)$ & \\
\hline >1000 copies/ml & $5(2.0)$ & $4(1.6)$ & \\
\hline Serum albumin $(\mathrm{g} / \mathrm{l})$ & $32(7)$ & $32(10)$ & $0(-2$ to 2$)$ \\
\hline Increase in serum albumin (g/l) & $6(7)$ & $6(3)$ & $0(-1$ to 1$)$ \\
\hline Haemoglobin (g/l) & $112(17)$ & $113(15)$ & $-1(-4$ to 2$)$ \\
\hline Increase in haemoglobin $(\mathrm{g} / \mathrm{l})$ & $15(21)$ & $13(20)$ & $2(-2$ to 6$)$ \\
\hline \multicolumn{4}{|l|}{ Quality of life: } \\
\hline General health ( $1=$ excellent, $5=$ poor) & $3.1(1.0)$ & $3.0(1.0)$ & $0.1(-0.1$ to 0.3$)$ \\
\hline Physically unhealthy days/month & $5.5(8.0)$ & $5.7(8.4)$ & $-0.2(-1.7$ to 1.3$)$ \\
\hline Mentally unhealthy days/month & $2.6(5.5)$ & $2.5(5.7)$ & $0.1(-0.9$ to 1.1$)$ \\
\hline Mental/physical limitation days/month & $4.2(8.8)$ & $4.2(8.8)$ & $0(-1.6$ to 1.6$)$ \\
\hline
\end{tabular}

Table 4 | Summary of mutually adjusted Cox regression modelling of death $\dagger$

\begin{tabular}{|c|c|}
\hline Independent variable & Hazard ratio $\ddagger(95 \% \mathrm{Cl})$ \\
\hline Male sex & $1.75(1.32 \text { to } 2.31)^{*}$ \\
\hline Age (years) & 1.01 (1.00 to 1.02$)$ \\
\hline BMI & $0.82(0.76 \text { to } 0.89)^{\star}$ \\
\hline Fat-free body mass (kg) & 0.99 (0.97 to 1.02$)$ \\
\hline No co-trimoxazole prophylaxis§ & $1.61(1.29 \text { to } 2.01)^{\star}$ \\
\hline CD4 count (cells $\left.\times 10^{6} / \mathrm{l}\right)$ & $1.00(0.99$ to 1.01$)$ \\
\hline Haemoglobin (g/l) & $0.88(0.83 \text { to } 0.94)^{*}$ \\
\hline Albumin (g/l) & $0.45(0.37 \text { to } 0.55)^{\star}$ \\
\hline Received fortified spread & $0.91(0.73$ to 1.14$)$ \\
\hline \multicolumn{2}{|c|}{$\begin{array}{l}\text { *P<0.05. } \\
\dagger \text { Enter mode used (that is, model includes all independent variable } \\
\text { specified at onset) } x^{2}=226, \mathrm{df}=9 \text {, for model, } P<0.001 \text {. } \\
\ddagger \text { Exponentiated } \beta \text { coefficient corresponds to hazard ratio, which } \\
\text { corresponds to factor by which chance of death increases with increase } \\
\text { in } 1 \text { unit in independent variable. Hazard ratio }<1 \text { indicates that as } \\
\text { independent variable decreases, risk of death increases. } \\
\S \text { Did not receive co-trimoxazole prophylaxis at any time during study } \\
\text { period. }\end{array}$} \\
\hline
\end{tabular}

board in Malawi because it is national policy to give supplementary food to wasted patients with HIV/ AIDS. Given that the benefits of a specialised energydense supplementary food were limited to improved nutritional status, these results highlight the need for a randomised controlled trial of the provision of supplementary food to wasted adults with HIV compared with the provision of no food to understand what benefits supplementary feeding of any type confers. Only $3 \%$ of participants were lost to follow-up, which is low compared with other studies of individuals with HIV in sub-Saharan Africa.

The analysis of the change in BMI with time indicates that during every interval in the 14 weeks study period, participants receiving fortified spread gained more BMI than those receiving corn-soy blend. This suggests that fortified spread conferred a differential benefit to participants over corn-soy blend throughout the entire study period, rather simply in the first few weeks.

In Africa antiretroviral therapy, particularly regimens including stavudine, is associated with metabolic side effects such as lipodystrophy, dyslipidaemias, and insulin resistance in individuals with $\mathrm{BMI} \geq 25 .^{23}$ Ready-to-use fortified spread is a food with a high fat content. We chose to give the supplementary food for a short, fixed duration of 14 weeks, to avoid putting patients who would have recovered from their wasting at an increased risk of metabolic complications.

Fat-free mass contributed about the same fraction of the weight gain in each food group, suggesting that more of the fortified spread was consumed than cornsoy blend. Fortified spread might have promoted greater weight gain than corn-soy blend because of its higher energy density, thereby allowing adequate energy intake in patients with some degree of anorexia. In addition, the focus group discussions indicated that fortified spread was shared less often. Fortified spread is ready to be eaten, while corn-soy blend needs to be cooked. Food preparation for ill adults with HIV/ 


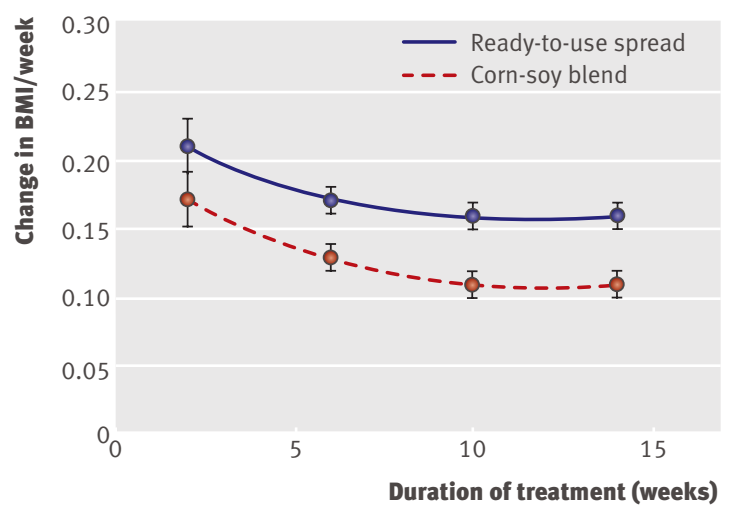

Fig 2 Analysis of rate of BMI change for fortified spread $v$ corn-soy blend. Data points represent mean ( $95 \%$ confidence interval)

AIDS will often be done by relatives or dependents, a practice that might be more conducive to sharing of the supplementary food. Corn-soy blend is similar to components of the traditional diet, while fortified spread is regarded as a special supplement for patients, a medicinal food. This cultural view of supplementary foods might have encouraged greater sharing of corn-soy blend.

The habitual diets of the participants were poor; only $30 \%$ achieved a dietary diversity score of $4 / 12$, indicating a high prevalence of food insecurity in this population. When we examined the change in BMI in subgroups of those deemed to have a better or worse diet, there were no differences in the response to the supplementary food observed (table 5). Thus, we found no evidence that those with a worse diet would benefit more from an energy dense food than those with a better diet.

\section{Comparisons of clinical outcomes with other studies}

Our findings are consistent with some previous observations of supplementary feeding with energy dense foods in people with HIV. Severely malnourished Malawian children with HIV who received fortified spread had greater weight-for-height improvement than those receiving corn-soy blend..$^{15}$ Adults with AIDS in urban Malawi given vegetable oil and cornsoy blend had greater improvement in BMI than those receiving corn-soy blend alone. ${ }^{12}$ Findings from an antiretroviral therapy programme in rural Malawi that provided corn-soy blend as a supplementary food in 2003 and fortified spread in 2004 indicate that patients receiving fortified spread had greater weight gain (1.5 $v 0.8 \mathrm{~kg} /$ month; $\mathrm{P}=0.04)$ (Kaliwo G. Use of RUTF in Thyolo district. CTC workshop, 25 June 2004, Lilongwe, Malawi). Our study is novel in that it provides evidence that an energy dense food is associated with improved recovery from wasting, though our results need confirmation in other populations with HIV.

Our data do not show a survival benefit associated with either of the supplementary foods. As the study was underpowered to detect differences in survival smaller than 5\%, we might have failed to detect a small survival benefit during the intervention period. Furthermore, as low BMI is an independent risk factor for death, ${ }^{82425}$ surviving patients who received supplementary fortified spread, and who are more likely to have a higher BMI, might have a better prognosis as they continue antiretroviral therapy.

In our high risk study population we observed a mortality rate of $27 \%$ in the first 14 weeks of antiretroviral therapy. High early mortality rates are common in antiretroviral therapy programmes in subSaharan Africa. In a study from rural Malawi, the mortality rate in the first three months of antiretroviral therapy was $26 \%$ in patients with severe malnutrition. ${ }^{8}$ In another rural district of Malawi the mortality was $14.6 \%$ among all patients in the first six months, and among those with $\mathrm{BMI}<18.5$ the relative risk of death was 3.56. ${ }^{24}$ The three month mortality among all patients starting antiretroviral therapy in studies from Senegal, Uganda, and Zambia was 7.6\%, 6.4\%, and $6.3 \%$, respectively. Low BMI was identified as a risk factor of death in all three studies, increasing the risk of death by two to threefold. ${ }^{25-27}$ The high mortality rate seen in our study highlights the importance of wasting as a risk factor for death in people with HIV starting antiretroviral therapy.

One difference between our study and the previous reports was the irregular availability of co-trimoxazole prophylaxis in Blantyre. A study from Malawi showed that co-trimoxazole prophylaxis can reduce early mortality during antiretroviral therapy, ${ }^{28}$ and indeed the regression analysis in our study indicated that the absence of co-trimoxazole prophylaxis was a strong risk factor for death. This suggests that invasive bacterial infections might have been an important cause of mortality, an observation found in other studies of early mortality on antiretroviral therapy from subSaharan Africa. ${ }^{272930}$ The high mortality rate in our study might also have been because of undiagnosed opportunistic infections present at enrolment. Tuberculosis is highly prevalent in Malawi, often presents

Table 5 Mean (SD) change in BMI after 14 weeks stratified by quality of initial diet

Fortified spread Corn-soy blend

Animal products:

None consumed yesterday $2.1(1.8)(n=113) \quad 1.6(1.6)(n=124)$

Consumed yesterday $2.5(2.0)(n=43) \quad 1.9(1.6)(n=42)$

$\begin{array}{lll}P \text { value } & 0.17 & 0.37\end{array}$

No of different foods consumed yesterday:

\begin{tabular}{lcc}
\hline $0-6$ & $2.2(1.6)(n=41)$ & $1.7(1.6)(n=55)$ \\
\hline $7-9$ & $2.1(2.2)(n=53)$ & $1.6(1.7)(n=59)$ \\
\hline $10-20$ & $2.2(1.7)(n=62)$ & $1.5(1.6)(n=52)$ \\
\hline$P$ value & 0.97 & 0.83 \\
\hline
\end{tabular}

Dietary diversity score ${ }^{19}$ :

\begin{tabular}{lcc}
1 (lowest)-2 & $2.0(1.9)(n=56)$ & $1.8(0.4)(n=56)$ \\
\hline 3 & $2.3(1.8)(n=54)$ & $1.4(1.6)(n=52)$ \\
\hline $4-12$ & $2.2(2.0(n=46)$ & $1.7(1.6)(n=58)$ \\
\hline$P$ value & 0.85 & 0.49
\end{tabular}




\section{WHAT IS ALREADY KNOWN ABOUT THIS TOPIC}

Many patients with HIV in sub-Saharan Africa are wasted and are commonly given supplementary food

The cost of supplementary feeding is considerable for HIV treatment programmes in subSaharan Africa

\section{WHAT THIS STUDY ADDS}

When wasted adults with HIV who are starting antiretroviral therapy are given a specialised ready-to-use lipid based fortified spread for 14 weeks they regain BMI more quickly than when given corn-soy flour

No differences were observed in mortality, CD4 count, viral load, HIV suppression, adherence to antiretroviral therapy, or quality of life between the food groups

atypically in patients with advanced immune suppression, and can give a clinical picture of wasting syndrome. It is an important cause of mortality in the first six months of antiretroviral therapy in patients in sub-Saharan Africa. ${ }^{31}$ At the start of treatment emaciated patients might benefit from more careful clinical screening for opportunistic infections, particularly tuberculosis. In addition, the effect of supplementary feeding on mortality might be more remarkable in a clinical setting where optimal management of opportunistic infections takes place.

The mean increase in CD 4 count of 157 cells $\times 10^{6} / 1$ among surviving participants compares favourably with data in other reports from sub-Saharan Africa; similar increases were reported one year after starting antiretroviral therapy in Malawi and Zambia. ${ }^{24} 25$

\section{Cost comparisons}

The corn-soy blend provided in our study cost $\$ 5.40$ $(£ 3.58, € 4.06)$ per patient per month, while fortified spread was three times as expensive at $\$ 16$. The Malawian government obtains the first line antiretroviral therapy for $\$ 15$ per patient per month. About a third of all adults starting antiretroviral therapy in Blantyre are wasted, so provision of supplementary food is a considerable expense. We did not measure the long term clinical benefits of supplementary feeding in this study. Formal cost benefit analyses are required to determine whether supplementary feeding strategies are cost effective when compared with other elements of clinical care given to those with HIV in sub-Saharan Africa.

We have shown that an energy dense supplement given to wasted adults starting antiretroviral therapy promotes better nutritional recovery in 14 weeks. Follow-up over a longer period of time is warranted to determine if the anthropometric benefits conferred by specialised energy dense supplements will lead to improved clinical outcomes.

We thank the patients for their participation in the study and the clinic staff at the Queen Elizabeth Central Hospital ART whose support enabled this study.

Contributors: MN and MJM designed the study and secured funding. MN JJVO, MJM planned the implementation. JJVO and EEZ advised on study design, data collection, and patient management. MN collected the data. MN, MJM, and MM analysed the data. MN, JJVO, and MJM wrote the first draft of the paper. All authors contributed to the final text. MJM is guarantor.

Funding: This study was supported by the USAID funded Food and Nutrition Technical Assistance (FANTA) Project of the Academy for Educational Development (AED) and AIDS Care Research in Africa (ACRiA). The AED provided expert review before making a funding decision, and the comments of those reviewers were considered in formulation of the final design. After agreeing to fund the study, neither sponsor played a role in the implementation, data collection, data analyses, or writing of this report.

Competing interests: None declared.

Ethical approval: The study was approved by the college of medicine research and ethics committee, University of Malawi, the human studies committee of the Washington University School of Medicine, and the committee for research on human subjects at the University of the Witwatersrand.

1 Dannhauser A, van Staden AM, van der Ryst E, Nel M, Marais N, Erasmus E, et al. Nutritional status of HIV-1 seropositive patients in the Free State Province of South Africa: anthropometric and dietary profile. Eur J Clin Nutr 1999;53:165-73.

2 Van der Sande MAB, van der Loeff MFS, Aveika AA, Sabally S, Togun T, Sarge-Njie R, et al. BMI at time of HIV diagnosis: a strong and independent predictor of survival. J Acquir Immune Defic Syndr 2004;37:1288-94.

3 Leyna GH, Mnyika KS, Mmbaga EJ, Hussain A, Klouman E, Holm-Hansen C, Klepp KI. Food insufficiency in rural Kilimanjaro, Tanzania. East Afr Med / 2007;84:163-71.

4 Mwaniki A. Achieving food security in Africa: challenges and issues. www.un.org/africa/osaa/reports/Achieving\%20Food\%20Security\% 20in\%20Africa-Challenges\%20and\%20Issues.pdf.

5 Bukusuba J, Kikafunda JK, Whitehead RG. Food security status in households of people living with HIV/AIDS (PLWHA) in a Ugandan urban setting. Br / Nutr 2007;98:211-7.

6 Au JT, Kayitenkore K, Shutes E, Karita E, Peters PJ, Tichacek A, et al. Access to adequate nutrition is a major potential obstacle to antiretroviral adherence among HIV-infected individuals in Rwanda. AIDS 2006;20:2116-8.

7 Hardon AP, Akurut D, Comoro C, Ekezie C, Irunde HF, Gerrits T, et al. Hunger, waiting time and transport costs: time to confront challenges to ART adherence in Africa. AIDS Care 2007;19:658-65.

8 Zachariah R, Fitzgerald M, Massaquoi M, Pasulani O, Arnould L, Makombe S, et al. Risk factors for high early mortality in patients on antiretroviral treatment in a rural district of Malawi. AIDS 2006;20:2355-60.

9 Mahlungulu S, Grobler LA, Visser ME, Volmink J. Nutritional interventions for reducing morbidity and mortality in people with HIV. Cochrane Database Syst Rev 2007;(3):CD004536.

10 Tjon A Ten WE, Kusin JA, DeWith C. The effects on weight and attendance of a supplementary feeding programme operating in two under-5 clinics in Lesotho. Ann Trop Paediatr 1990;10:411-9.

11 Caulfield LE, Huffman SL, Piwoz EG. Interventions to improve intake of complementary foods by infants 6 to 12 months of age in developing countries: impact on growth and on the prevalence of malnutrition and potential contribution to child survival. Food Nutr Bull 1999;21:183-200.

12 Bowie C, Kalilani L, Marsh R, Misiri H, Cleary P, Bowie CT. An assessment of food supplementation to chronically sick patients receiving home based care in Bangwe, Malawi: a descriptive study. Nutr J 2005;4:12.

13 Manary M. Local production and provision of ready-to-use therapeutic food (RUTF) spread for the treatment of severe malnutrition. Food Nutr Bull 2006;27:S83-8.

14 Ciliberto MA, Sandige H, Ndekha MJ, Ashorn P, Briend A, Ciliberto HM, et al. A comparison of home-based therapy with readyto-use therapeutic food with standard therapy in the treatment of malnourished Malawian children: a controlled, clinical effectiveness trial. Am J Clin Nutr 2005;81:864-70.

15 Ndekha MJ, Manary MJ, Ashorn P, Briend A. Home-based therapy with ready-to-use therapeutic food is of benefit to malnourished, HIV-infected Malawian children. Acta Paed 2005;94:222-5.

16 ORC Macro. Malawi demographic and health survey 2004. Zomba, Malawi: National Statistical Office, 2005.

17 Centers for Disease Control and Prevention. Measuring healthy days. Atlanta: CDC, 2000.

18 Van Oosterhout JJ, Bodasing N, Kumwenda J, Nyirenda C, Cleary PR, Mallewa J, et al. Evaluation of antiretroviral therapy results in a resource-poor setting in Blantyre, Malawi. Trop Med Int Health 2005;10:464-70.

19 HoddinottJ, Yohannes Y. Dietary diversity as a food security indicator. Washington, DC: International Food Policy Research Institute, 2002. (FCND Discussion Paper No 136.) 
20 World Health Organization. Nutrient requirements for people living with HIV/AIDS Report of a technical consultation. Geneva, Switzerland: WHO, 2003.

21 Kotler DP, Burastero S, Wang J, Pierson RN Jr. Prediction of body cell mass, fat-free mass, and total body water with bioelectrical impedance analysis: effects of race, sex, and disease. Am J Clin Nutr 1996;64(3 suppl):489-97S.

22 Waterlow JC. Protein energy malnutrition. London: Edward Arnold, 1992.

23 Van Griensven J, De Naeyer L, Mushi T, Ubarijoro S, Gashumba D, Gazille C, et al. High prevalence of lipoatrophy among patients on stavudine-containing first-line antiretroviral therapy regimens in Rwanda. Trans R Soc Trop Med Hyg 2007;101:793-8.

24 Ferradini L, Jeannin A, Pinoges L, Izopet J, Odhiambo D, Mankhambo L, et al. Scaling up of highly active antiretroviral therapy in a rural district of Malawi: an effectiveness assessment: Lancet 2006;367:1335-42.

25 Stringer JS, Zulu I, Levy J, Stringer EM, Mwango A, Chi BH, et al. Rapid scale-up of antiretroviral therapy at primary care sites in Zambia: feasibility and early outcomes. JAMA 2006;296:782-93.

26 Liechty CA, Solberg P, Were W, Ekwaru JP, Ransom RL, Weidle PJ, et al. Asymptomatic serum cryptococcalantigenemia and early mortality in rural Uganda. Trop Med Int Health 2007;12:929-35.
27 Etard JF, Ndiaye I, Thierry-Mieg M, Guèye NF, Guèye PM, Lanièce I, et al. Mortality and causes of death in adults receiving highly active antiretroviral therapy in Senegal: a 7-year cohort study. AIDS 2006;20:1181-9.

28 Lowrance D, Makombe S, Harries A, Yu J, Aberle-Grasse J, Eiger O, et al. Lower early mortality rates among patients receiving antiretroviral treatment at clinics offering cotrimoxazole prophylaxis in Malawi. J Acquir Immune Defic Syndr 2007;46:56-61.

29 Moh R, Danel C, Messou E, Ouassa T, Gabillard D, Anzian A, et al. Incidence and determinants of mortality and morbidity following early antiretroviral therapy initiation in HIV-infected adults in West Africa. AIDS 2007;21:2483-91.

30 Lawn SD, Myer L, Harling G, Orrell C, Bekker LG, Wood R. Determinants of mortality and non-death losses from an antiretroviral treatment service in South Africa: implications for program evaluation. Clin Infect Dis 2006;43:770-6.

31 Moore D, Liechty C, Ekwaru P, Were W, Mwima G, Solberg P, et al. Prevalence, incidence and mortality associated with tuberculosis in HIV-infected patients initiating antiretroviral therapy in rural Uganda. AIDS 2007;21:713-9.

Accepted: 19 January 2009 